\title{
Diabetes and beta-adrenergic blockage are risk factors for metastatic prostate cancer
}

\author{
Malte Krönig ${ }^{1,4^{*}}$ (D), Christian Haverkamp ${ }^{3}$, Antonia Schulte ${ }^{1}$, Laura Heinicke ${ }^{1}$, Kathrin Schaal ${ }^{1}$, Vanessa Drendel ${ }^{2}$, \\ Martin Werner ${ }^{2}$, Ulrich Wetterauer ${ }^{1}$, Wolfgang Schultze-Seemann ${ }^{1}$ and Cordula Annette Jilg ${ }^{1}$
}

\begin{abstract}
Background: We evaluated the influence of comorbidity inferred risks for lymph node metastasis (pN1) and positive surgical margins (R1) after radical prostatectomy in order to optimize pretherapeutic risk classification. We analyzed 454 patients after radical prostatectomy (RP) between 2009 and 2014. Comorbidities were defined by patients' medication from our electronic patient chart and stratified according to the ATC WHO code. Endpoints were lymph node metastasis (pN1) and positive surgical margins (R1).

Results: Rates for pN1 and R1 were 21.4\% (97/454) and 29.3\% (133/454), respectively. In addition to CAPRA and Gleason score, we identified diabetes as a significant medication inferred risk factor for $p N 1$ (OR 2.9, $p=0.004 / O R$ $3.2, p=0.001 / \mathrm{OR} 3.5, p=0.001$ ) and beta-blockers for R1 (OR 1.9, $p=0.020 / \mathrm{OR} 2.9, p=0.004$ ). Patients with diabetes showed no statistically significant difference in Gleason score, CAPRA Score, PSA, and age compared to non-diabetic patients.

Conclusions: We identified diabetes and beta1 adrenergic blockage as significant risk factors for lymph node metastasis and positive surgical margins in prostate cancer (PCa). Patients at risk will need intensive pretherapeutic staging for optimal therapeutic stratification.
\end{abstract}

Keywords: Prostate cancer, Metastasis, Diabetes, Beta-adrenergic blockage

\section{Background}

Prostate cancer $(\mathrm{PCa})$ is the second most common cancer and third most leading cause of death of men in the western world [1]. Correct risk stratification is crucial for optimal of high-risk patients and avoiding overtreatment in low-risk patients. Risk stratification is based on histologic analysis of invasive prostate biopsies, which are indicated by elevated prostate-specific antigen (PSA) levels or suspicious digital rectal examination (DRE) findings. Several risk classification tools exist for pretherapeutic stratification such as Kattan normograms [2], D'Amico score [3, 4] or CAPRA (Cancer of Prostate Risk Assessment) score [5-7]. All scores are based primarily on PSA levels $(\mathrm{ng} / \mathrm{ml})$, Gleason score, and age (years) and have biochemical recurrence within 5 years

\footnotetext{
* Correspondence: malte.kroenig@uniklinik-freiburg.de

'Department of Urology, Uniklinikum Freiburg, Hugstetter Strasse 55, 79106 Freiburg, Germany

${ }^{4}$ Department of Urology, University of Freiburg Medical Centre, Hugstetter Strasse 55, 79106 Freiburg, Germany

Full list of author information is available at the end of the article
}

after radical prostatectomy as primary endpoint. The mentioned scores stratify patients into low-, intermediate-, and high-risk groups. However, identifying patients with preexisting lymph node metastases $(\mathrm{cN} 1)$ or non-organ defined tumors (R1) remains difficult, but these parameters significantly determine the therapeutic strategy. Imaging which provide detailed information for $\mathrm{cN}$ status and $\mathrm{R}$ status, such as magnetic resonance imaging (MRI) or positron emission computer tomography (PET/CT) (e.g., PSMA-PET/CT), cannot be performed in every patient for economic and availability reasons. $\mathrm{cN} 1$ status would require extended lymphadenectomy during radical prostatectomy or extended field radiation in primary radiation therapy. Extended staging using MRI is recommended for highrisk patients with PSA $>10 \mathrm{ng} / \mathrm{ml}$ or Gleason score $\geq 8-10$ [8] only in the European guidelines for prostate cancer. In order to find further risk stratifier, comorbidities have come into the focus with possible implications on cancer genesis, stage, progression, and therapy $[9,10]$. Data are 
still conflicting, and exact mechanism regarding stage and prognosis are not understood. Among the comorbidities, diabetes is one of the better examined and most common diseases with an estimated 269 million people affected worldwide [11]. Interestingly, a reduced risk for developing $\mathrm{PCa}$ has been described for diabetes patients [11]; however, little is known about the impact on cancer stage. We have therefore used our electronic patient chart to generate the prostate cancer patients' comorbidity profile by the self-medication during hospitalization for radical prostatectomy. We assessed the comorbidity profile's impact on cancer stage at diagnosis represented by $\mathrm{R}$ status and $\mathrm{pN}$ status as the key determinants of primary and adjuvant therapeutical strategy.

\section{Methods}

We included 454 patients with prostate cancer, who were treated with radical prostatectomy (RP) between 2009 and 2014 (median age 66 years, interquartile range (IQR 61.0-71.0). The same surgical team operated these patients with equal experience. Comorbidities were defined by patients' self-medication during hospitalization for radical prostatectomy. Medications were generated from our electronic patient chart (Meona $\odot)$ and stratified according to the ATC (Anatomic Therapeutic Chemical) WHO code at the time of the RP.

\section{ATC code}

Anatomical Therapeutic Chemical (ATC) classification system divides the active substances into different groups according to the organ or system on which they act and their therapeutic, pharmacological, and chemical properties. Drugs are classified in groups at five different levels. The drugs are divided into 14 main groups $\left(1^{\text {st }}\right.$ level), with pharmacological/therapeutic subgroups $\left(2^{\text {nd }} l e v e l\right)$. The $3^{\text {rd }}$ and $4^{\text {th }}$ levels are chemical/pharmacological/therapeutic subgroups, and the $5^{\text {th }}$ level is the chemical substance [12].

\section{CAPRA score}

Cancer of the Prostate Risk Assessment CAPRA [13-16] score was used for pretherapeutic risk classification. The score includes PSA at diagnosis $(\mathrm{ng} / \mathrm{ml})$, Gleason pattern of the biopsy (primary/secondary), age (years), and positive biopsy cores (percent of total number of biopsies) as variables (Additional file 1: Table S1), which are weighted differently according to the value.

\section{Endpoints}

Endpoints were lymph node metastasis (pN1) and positive surgical margins (R1) after radical prostatectomy based on the histopathologic analysis of the radical prostatectomy specimens including lymph nodes. Specimens were routinely processed, and analysis was performed on paraffin embedded, cut, and H\&E-stained samples.

\section{Statistics}

Descriptive statistics was done by calculating mean \pm standard deviation (SD), median, and interquartile range (IQR). Logistic and linear regression analyses were used for identifying risk factors using SPSS $\odot$ software (SPSS statistics 22, IBM) calculated as odds ratio (OR) and $p$ value.

Table 1 Patients' characteristics $(n=454)$

\begin{tabular}{|c|c|}
\hline \multicolumn{2}{|c|}{ Age at radical prostatectomy (years) } \\
\hline 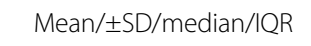 & $65.3 / 6.7 / 66.0 / 61.0-70.0$ \\
\hline \multicolumn{2}{|c|}{ PSA at radical prostatcetomy (ng/ml) } \\
\hline Mean/₫SD/median/IQR & 13.8/24.4/8.6/5.6-14.4 \\
\hline \multicolumn{2}{|l|}{ Gleason score at biopsy $(n)$} \\
\hline \multicolumn{2}{|l|}{$\%$ (n/total) } \\
\hline $8-10$ & $25.9(118 / 454)$ \\
\hline 7 & $62.3(283 / 454)$ \\
\hline 6 & $11.7(53 / 454)$ \\
\hline \multicolumn{2}{|c|}{ Gleason score at radical prostatectomy (n) } \\
\hline \multicolumn{2}{|l|}{$\%$ (n/total) } \\
\hline $8-10$ & $21.2(96 / 454)$ \\
\hline 7 & $60.6(275 / 454)$ \\
\hline 6 & $18.3(83 / 454)$ \\
\hline \multicolumn{2}{|l|}{ T stage at biopsy $(n)$} \\
\hline \multicolumn{2}{|l|}{$\%(n /$ total $)$} \\
\hline 4 & $1.9(9 / 454)$ \\
\hline 3 & $36.8(167 / 454)$ \\
\hline 2 & $61.2(278 / 454)$ \\
\hline \multicolumn{2}{|c|}{ T stage at radical prostatectomy $(n)$} \\
\hline \multicolumn{2}{|l|}{$\%$ (n/total) } \\
\hline 4 & $0.7(3 / 454)$ \\
\hline 3 & $34.8(158 / 454)$ \\
\hline 2 & $64.3(292 / 454)$ \\
\hline \multicolumn{2}{|l|}{ CAPRA score at biopsy $(n)$} \\
\hline \multicolumn{2}{|l|}{$\%$ (n/total) } \\
\hline 6-10 (high risk) & $41.4(188 / 454)$ \\
\hline 3-5 (intermediate risk) & $39.8(181 / 454)$ \\
\hline 1-2 (low risk) & $18.5(85 / 454)$ \\
\hline \multicolumn{2}{|l|}{$\begin{array}{l}\text { Positive lymph nodes }(\mathrm{N}+) \\
\text { at radical prostatectomy }(n)\end{array}$} \\
\hline$\%$ (n/total) & $21.3(97 / 545)$ \\
\hline \multicolumn{2}{|l|}{$\begin{array}{l}\text { Positive surgical margin }(\mathrm{R}+) \\
\text { at radical prostatectomy }(n)\end{array}$} \\
\hline$\%$ (n/total) & $29.3(133 / 454)$ \\
\hline
\end{tabular}




\section{Results}

Four hundred fifty-four prostate cancer patients after radical prostatectomy were analyzed in this study. Patients' median age was 66.0 years (IQR 61.0-70.0) and median iPSA $8.55 \mathrm{ng} / \mathrm{ml}$ (IQR 5.67-14.43). 18.5\% (85/ 454), 39.88\% (181/454), and 41.41\% (188/454) showed CAPRA score 1-2, 3-5 and 6-10, respectively. Histopathology from prostatectomy and lymphadenectomy showed in 11.7\% (53/454), 62.33\% (283/454), and 25.99\% (118/454) Gleason score 6, 7, and 8-10 (Table 1). Rates for pN1 and R1 were 21.37\% (97/454) and 29.30\% (133/ 454 ), respectively (Table 1 ).

A median of 2 (IQR 1-4) medications from 2 (IQR 14) comorbidity level 1 classes were taken per patient. $14.9 \%(68 / 454), 54.2 \%$ (246/454), $29.7 \%$ (135/454), and $1.1 \%(5 / 454)$ of the patients took $0,1-3,4-9$, and $10-15$ medications (Table 5). From clinical parameters such as age (years), PSA (ng/ml), Gleason score, and CAPRA score, we identified CAPRA score and Gleason score as significant risk factors for $\mathrm{N} 1$ (OR 3.200, $p=0.001 / \mathrm{OR}$ $3.454, p=0.001$ ) and CAPRA score for R1 (OR 2.916, $p=0.004$ ) (Table 4). Patients with diabetes showed no statistically significant difference in Gleason score $(p=$ $0.499)$, CAPRA score $(p=0.495)$, PSA $(p=0.668)$, and age $(p=0.537)$ compared to non-diabetic patients.

Patients took 157 different types of medications from 9 major comorbidity classes according to the ATC code level 1 [12] (Table 2). 14.89\% (68/454), 54.19\% (246/ $454), 29.74 \%(135 / 454)$, and $1.1 \%(5 / 454)$ took $0,1-3$, 4-9, and greater 10 medications at time of radical prostatectomy. Patients took medication for cardiovascular system (C) 68.28\% (310/454), alimentary tract (A) $33.70 \%$ (153/454), blood system (B) 27.53\% (125/454), genitourinary system (G) $12.78 \%$ (58/454), hormonal system $(\mathrm{H}) 10.35 \%(47 / 454)$, nervous system $(\mathrm{N})$ 8.81\% (40/ $454)$, respiratory system (R) $3.52 \%$ (16/454), sensory system (S) 3.08\% (14/454), and immune system (L) $0.66 \%$ (3/454) (Table 2).
Analysis of the ATC code on level 2 showed top 10 medications to be renin angiotensin system (C09) 44.49\% (202/454), beta-blockers (C07) 32.28\% (147(454), antithrombosis (B01) 27.53\% (125/454), lipid modifyers (C10) 26.21\% (110/454), acid disorders (A02) 23.57\% (107/454), calcium channel blockers (C08) 17.18\% (78/ 454), diuretics (C03) 14.32\% (65/454), urologicals (G04) $12.78 \%$ (58/454), thyroid therapy (H03) 10.13\%(46/454), and diabetes (A10) 9.25\% (42/454) (Table 3).

Logistic regression analysis on ATC code level 1 did not show significantly increased risk for $\mathrm{pN} 1$ or $\mathrm{R} 1$ status whereas regression analysis on ATC code level 2 did show significantly increased risk for $\mathrm{pN} 1$ in patients with diabetes (OR 2.869, $p=0.004$ ) and beta1 blockers for R1 (OR 1.929, $p=0.020$ ). Subgroup analysis showed significantly increased risk for $\mathrm{N} 1$ in patients taking metformin (OR 2.989, $p=0.010$ ) and R1 for patients taking beta1 selective blocker metoprolol (OR 2.400, $p=0.010$ ). The number of medications per patient and the number of medicated organ systems per patient did not show statistically significant risk increase for either N1 or R1 (Table 3).

\section{Discussion}

In this study, we identified diabetes (OR 2.869) and beta-blockage (OR 1.929) as significant risk factors for the existence of lymph metastases (pN1) and non-organ confined (R1) prostate cancer in patients at radical prostatectomy. The comorbidity profile of each patient was defined as the self-medication, which is not associated to hospitalization. More comorbidities might have been present within the cohort, which were missed by this method. However, our methods allow for a detailed analysis of the comorbidities on the organ system level down to single medications utilizing the WHO ATC code. Within the diabetes group, e.g., we identified metformin and in the beta1 selective blockage group metoprolol as single risk factors for $\mathrm{pN} 1$ and $\mathrm{R} 1$, respectively.

Table 2 Characteristics of comorbidities (ATC code level 1, distribution and regression analyses)

\begin{tabular}{|c|c|c|c|}
\hline \multirow[t]{2}{*}{ ATC code level 1} & Distribution & Positive surgical margin (R1) & Lymph node metasasis (N1) \\
\hline & $\%$ (n/total) & $\mathrm{OR} / p$ value & $\mathrm{OR} / p$ value \\
\hline Cardiovascular system C & $68.28(310 / 454)$ & $1.164 / 0.531$ & $0.904 / 0.715$ \\
\hline Alimentary tract A & $33.70(153 / 454)$ & $0.864 / 0.525$ & $1.370 / 0.203$ \\
\hline Blood system B & $27.53(125 / 454)$ & $1.068 / 0.789$ & $1.927 / 0.63$ \\
\hline Urinary system $G$ & $12.78(58 / 454)$ & $0.748 / 0.382$ & $1.263 / 0.480$ \\
\hline Hormonal system H & $10.35(47 / 454)$ & $1.356 / 0.355$ & $1.203 / 0.621$ \\
\hline Nervous system N & $8.81(40 / 454)$ & $1.662 / 0.148$ & $1.214 / 0.617$ \\
\hline Respiratory system R & $3.52(16 / 454)$ & $1.305 / 0.622$ & $0.431 / 0.283$ \\
\hline Sensory system S & $3.08(14 / 454)$ & $2.284 / 0.139$ & $0.913 / 0.894$ \\
\hline Immune system L & $0.66(3 / 454)$ & $1.216 / 0.875$ & $0.000 / 0.999$ \\
\hline
\end{tabular}

ATC level 1: level 1 of the Anatomic Therapeutic Chemical (ATC) code describes anatomic organ systems; OR odds ratio 
Table 3 Characteristics of comorbidities (ATC code level 2, distribution and regression analyses)

\begin{tabular}{|c|c|c|c|c|}
\hline \multirow{2}{*}{$\begin{array}{l}\text { ATC code } \\
\text { level } 2\end{array}$} & \multirow[t]{2}{*}{ Comorbidity system } & \multirow{2}{*}{$\begin{array}{l}\text { Distribution } \\
\%(n / n)\end{array}$} & \multirow{2}{*}{$\begin{array}{l}\text { Positive surgical margin (R1) } \\
\text { OR/p value }\end{array}$} & \multirow{2}{*}{$\begin{array}{l}\text { Lymph node metastasis ( } \mathrm{N} 1 \\
\mathrm{OR} / \mathrm{p} \text { value }\end{array}$} \\
\hline & & & & \\
\hline C09 & Renin angiotensin system & $44.5(202 / 454)$ & 0.999/0.997 & $1.344 / 0.255$ \\
\hline $\mathrm{CO7}$ & Beta-blockers & $32.3(147(454)$ & $1.929 / 0.020$ & $0.953 / 0.878$ \\
\hline B01 & Antithrombosis & $27.5(125 / 454)$ & $1.063 / 0.829$ & $1.821 / 0.52$ \\
\hline $\mathrm{C} 10$ & Lipid modifiers & $26.2(110 / 454)$ & $0.867 / 0.616$ & $0.982 / 0.995$ \\
\hline $\mathrm{A} 02$ & Acid disorders & $23.6(107 / 454)$ & $0.954 / 0.860$ & $1.127 / 0.679$ \\
\hline $\mathrm{C} 08$ & Calcium channel blockers & $17.2(78 / 454)$ & $0.702 / 0.311$ & $0.523 / 0.126$ \\
\hline $\mathrm{CO3}$ & Diuretics & $14.3(65 / 454)$ & $1.174 / 0.626$ & $0.779 / 0.510$ \\
\hline G04 & Urologicals & $12.8(58 / 454)$ & $0.653 / 0.232$ & $1.346 / 0.387$ \\
\hline $\mathrm{H} 03$ & Thyroid therapy & $10.1(46 / 454)$ & $1.227 / 0.557$ & $1.253 / 0.559$ \\
\hline $\mathrm{A} 10$ & Diabetes & $9.3(42 / 454)$ & $1.092 / 0.811$ & $2.869 / 0.004$ \\
\hline $\mathrm{A} 07$ & Diarrhea, inflammation & $5.1(23 / 454)$ & $0.240 / 0.074$ & $0.515 / 0.387$ \\
\hline N06 & Psychoanaleptics & $4.4(20 / 454)$ & $1.172 / 0.761$ & $0.761 / 0.653$ \\
\hline $\mathrm{C} 01$ & Cardiac therapy & $3.9(18 / 454)$ & $0.559 / 0.346$ & $0.550 / 0.396$ \\
\hline R03 & Anti asthmatics & $3.3(15 / 454)$ & $1.009 / 0.989$ & $0.143 / 0.148$ \\
\hline N05 & Psycholeptics & $3.1(14 / 454)$ & $1.114 / 0.860$ & $2.254 / 0.177$ \\
\hline $\mathrm{CO2}$ & Antihypertensives & $2.6(12 / 454)$ & $0.220 / 0.158$ & $1.459 / 0.619$ \\
\hline N03 & Antiepileptics & $1.8(8 / 454)$ & $6.048 / 0.051$ & $2.824 / 0.306$ \\
\hline S01 & Opthalmologicals & $1.5(7 / 154)$ & $2.560 / 0.334$ & $0.755 / 0.875$ \\
\hline A03 & Functional gastroint, disorders & $0.7(3 / 454)$ & $2.778 / 0.476$ & $1.078 / 0.963$ \\
\hline L04 & Immunosuppression & $0.7(3 / 454)$ & $3.537 / 0.361$ & 0.0/0.999 \\
\hline N04 & Anti parkinson drugs & $0.7(3 / 454)$ & $3.956 / 0.276$ & $0.0 / 0.999$ \\
\hline $\mathrm{A} 01$ & Stomatologic disorders & $0.4(2 / 454)$ & 0.0/0.999 & $1.770 / 0.770$ \\
\hline R01 & Nasal corticoides & $0.4 / 2 / 454)$ & 0.0/0.999 & $10.577 / 0.287$ \\
\hline \multicolumn{5}{|l|}{ Subgroupanalysis } \\
\hline \multirow[t]{2}{*}{ Diabetes } & Insulin & $4.2(19 / 454)$ & - & 1090/0.882 \\
\hline & Metformin & $7.7(35 / 454)$ & - & $2.989 / 0.009$ \\
\hline \multirow[t]{4}{*}{ Beta-blockers } & Carvedilol & $1.9(9 / 454)$ & $0.341 / 0.314$ & - \\
\hline & Metoprolol & $8.9(40 / 454)$ & $2.400 / 0.010$ & - \\
\hline & Bisoprolol & $14.8(67 / 454)$ & $1.202 / 0.533$ & - \\
\hline & Nebivolol & $2.4(11 / 454)$ & $2.884 / 0.090$ & - \\
\hline
\end{tabular}

ATC level 2: level 2 of the Anatomic Therapeutic Chemical (ATC) code describes anatomic or chemical systems within the body or in specific organs; OR odds ratio; italic $=$ statistically significant $\mathrm{OR}$

Comorbidities have been associated with tumor genesis and progression, results however remain controversial. Several studies show that the effect can be protective or associated with increased cancer risk in different organs [17]. Especially, diabetes and betaadrenergic signaling have been associated with carcinogenesis for a long time.

Lipscomb et al. [18] showed that diabetic women $(n$ $=6115$ ) have an increased risk (OR 1.16) for developing lymph node positive breast cancer. Obesity or increased BMI are not associated with increased risk for lymph node metastases [19] in breast cancer. We could not identify a study, which specifically analyzed the association between diabetes and nodal status of prostate cancer in a PubMed search until today.

Several studies describe a medication inferred decreased risk for developing prostate cancer: Margel et al. [20] showed in 12,000 prostate cancer patients that, e.g., metformin users had decreased risk (OR 0.66) for developing prostate cancer. Preston et al. [21] showed in 120,000 diabetic men that metformin was not associated with decreased risk for developing prostate cancer in general or high-grade prostate cancer. A meta-analysis by Bansal et al. [22] concluded from 8.1 million patients including 120,000 prostate cancer patients that diabetes significantly lowers the risk (RR 0.86) for developing 
prostate cancer. Li et al. [23] report opposite results in a cohort of 22,000 men with increased risk for developing high-grade prostate cancer in men with diabetes.

Despite the high numbers of studies showing a protective effect of diabetes on cancer genesis, little is known about the influence of diabetes in men with prostate cancer. Also, on the mechanistic level, it was shown that diabetes alters the lymphatic vessel architecture and promotes vessel evasion of the tumor cells [24]. Our clinical findings could be explained by the latter results (Table 4). However, further studies have to validate our findings.

Also, beta-adrenergic signaling has been associated with advanced prostate cancer [25] and beta-blockers have been associated reduced mortality in various tumor types [25]. The prostate, especially the peripheral zone where most of the tumors originate, shows high adrenergic innervation [25]. Especially, beta2 receptor subtypes were detected in the peripheral zone. This could explain a possible protective effect by unselective beta-blockage such as carvedilol; however, the effect in our analysis was statistically not significant. The luminal epithelial cells which are suspected as the originating cells for prostate cancer show high expression for betaadrenergic receptors in the malignant and benign state and thus connect the nervous system to the tumor [26]. Magnon et al. [27] showed that beta-adrenergic and cholinergic nerves play an important role in prostate cancer genesis and progression, by actively infiltrating the tumor. Perineural nerve sheath infiltration by the tumor also serves as an independent negative predictor for disease free survival [28]. Furthermore, betablockers were associated, we improved survival in prostate cancer patients [29]. Even though beta-blockers seem to have protective effects on long term survival, the underlying disease with an activated adrenergic system could well explain the increased risk for R1 disease in prostate cancer patients in our cohort. Further studies will have validate our results. Only scarce data is available upon alpha-adrenergic signaling and cancer. Some studies show inhibitory effects on cancer cells by alpha-adrenergic blockage [30-32].

Table 4 Regression analysis for clinical risk factors

\begin{tabular}{lll}
\hline Variables & Positive surgical margin (R1) & $\begin{array}{l}\text { Lymph node } \\
\text { metasasis (N1) } \\
\text { OR/ } p \text { value }\end{array}$ \\
\hline Age (years) & $0.987 / 0.334$ & $1.623 / 0.105$ \\
PSA (ng/ml) & $0.848 / 0.397$ & $1.140 / 0.255$ \\
$\begin{array}{l}\text { Gleason score } \\
\text { (6-10) }\end{array}$ & $1.037 / 0.300$ & $3.454 / 0.001$ \\
$\begin{array}{l}\text { CAPRA score } \\
\text { (1-5) }\end{array}$ & $2.916 / 0.004$ & $3.200 / 0.001$ \\
\hline PSA prostate &
\end{tabular}

PSA prostate specific antigen, CAPRA Cancer of the Prostate Risk Assessment; $O R$ odds ratio; italic $=$ statistically significant $\mathrm{OR}$
Table 5 Medication characteristics per patient

Number of mediaction systems/patient

mean/ \pm SD/median/IQR

$2.544 / 2.059 / 2.0 / 1-4$

Number of medications/patient

mean/ $\pm \mathrm{SD} /$ median/IQR

$2.7 / 2.322 / 2.0 / 1-4$

Number of medications/patient

$\%(n /$ total $)$

$10-15$

4-9

$29.7(135 / 454)$

$1-3$

$54.2(246 / 454)$

0

$14.9(68 / 454)$

Limitation of this study is the fact that comorbidities were defined only by self-medication. Additional comorbidities not reflected by the medication were not analyzed. Furthermore, dosage and duration of the medications were not considered.

We were able to show that together with the established stratification markers such as Gleason score or the CAPRA score, medication profiles can further aid in identifying men at high risk for advanced and aggressive prostate cancer (Table 5).

\section{Conclusions}

Diabetes and beta-blockage are major risk factors for advanced prostate cancer, which should be incorporated into the pretherapeutic staging strategy and into the planning of definite therapy to allow for optimal results for our patients. The usage of electronic patient charts represent a powerful tool to analyze risk structures within patient cohorts. They could also be used to incorporate medication-based risk factors, which will automatically alert the physicians for high-risk patients.

\section{Additional file}

Additional file 1: Medication characteristics ( $n=157)$. (DOCX 20 kb)

Acknowledgements

Does not apply.

Funding

The study has been funded from the Department of Urology itself.

Availability of data and materials

All data will be available upon request from the authors.

Authors' contributions

MK and CJ designed the study, analyzed the data, and wrote the manuscript. $\mathrm{CH}, \mathrm{AS}, \mathrm{KS}$, and LH acquired the medication data. VD and MW performed histologic analysis of the radical prostatectomy specimens. UW, CJ, and WS performed radical prostatectomies. All authors read and approved the final manuscript.

Competing interests

The authors declare that they have no competing interests. 


\section{Consent for publication}

The study does not use personalized data, and hence, a consent for publication does not apply.

\section{Ethics approval and consent to participate}

All patient gave written consent prior to data collection. The study has been approved by the Ethics Committee of the University of Freiburg (Engelberger Straße 2179106 Freiburg) under the reference number 416/11.

\section{Author details}

'Department of Urology, Uniklinikum Freiburg, Hugstetter Strasse 55, 79106 Freiburg, Germany. ${ }^{2}$ Institut of Clinical Pathology, Uniklinikum Freiburg, Breisacher Strasse 115a, 79106 Freiburg, Germany. ${ }^{3}$ IT-Department, Uniklinikum Freiburg, Agnesenstrasse 6-8, 79106 Freiburg, Germany ${ }^{4}$ Department of Urology, University of Freiburg Medical Centre, Hugstetter Strasse 55, 79106 Freiburg, Germany.

\section{Received: 4 October 2016 Accepted: 8 February 2017}

\section{Published online: 21 February 2017}

\section{References}

1. Howlader N NA, Krapcho M, Miller D, Bishop K, Altekruse SF, Kosary CL, Yu M, Ruhl J, Tatalovich Z, Mariotto A, Lewis DR, Chen HS, Feuer EJ, Cronin KA (eds). SEER Cancer Statistics Review, 1975-2013, National Cancer Institute. Bethesda, MD, http://seer.cancer.gov/csr/1975_2013/, based on November 2015 SEER data submission, posted to the SEER web site, April 2016. 2016.

2. Shariat SF, Karakiewicz Pl, Roehrborn CG, Kattan MW. An updated catalog of prostate cancer predictive tools. Cancer. 2008;113:3075-99.

3. Hernandez DJ, Nielsen ME, Han M, Partin AW. Contemporary evaluation of the D'amico risk classification of prostate cancer. Urology. 2007;70:931-5.

4. D'Amico AV, Whittington R, Malkowicz SB, Schultz D, Blank K, Broderick GA, Tomaszewski JE, Renshaw AA, Kaplan I, Beard CJ, Wein A. Biochemical outcome after radical prostatectomy, external beam radiation therapy, or interstitial radiation therapy for clinically localized prostate cancer. JAMA. 1998;280:969-74.

5. Rodrigues G, Warde P, Pickles T, Crook J, Brundage M, Souhami L, Lukka H, Genitourinary Radiation Oncologists of C. Pre-treatment risk stratification of prostate cancer patients: a critical review. Can Urol Assoc J. 2012:6:121-7.

6. Cooperberg MR, Broering JM, Carroll PR. Risk assessment for prostate cancer metastasis and mortality at the time of diagnosis. J Natl Cancer Inst. 2009; 101:878-87.

7. Cooperberg MR, Pasta DJ, Elkin EP, Litwin MS, Latini DM, Du Chane J, Carroll PR. The University of California, San Francisco Cancer of the Prostate Risk Assessment score: a straightforward and reliable preoperative predictor of disease recurrence after radical prostatectomy. J Urol. 2005:173:1938-42.

8. Heidenreich A, Bastian PJ, Bellmunt J, Bolla M, Joniau S, van der Kwast T, Mason M, Matveev V, Wiegel T, Zattoni F, et al. EAU guidelines on prostate cancer. part 1: screening, diagnosis, and local treatment with curative intent-update 2013. Eur Urol. 2014;65:124-37.

9. Hall WH, Jani AB, Ryu JK, Narayan S, Vijayakumar S. The impact of age and comorbidity on survival outcomes and treatment patterns in prostate cancer. Prostate Cancer Prostatic Dis. 2005;8:22-30.

10. Gurney J, Sarfati D, Stanley J. The impact of patient comorbidity on cancer stage at diagnosis. Br J Cancer. 2015;113:1375-80.

11. Giovannucci E, Harlan DM, Archer MC, Bergenstal RM, Gapstur SM, Habel LA, Pollak M, Regensteiner JG, Yee D. Diabetes and cancer: a consensus report. Diabetes Care. 2010;33:1674-85.

12. WHO. Anatomic therapeutic chemical code (ATC). 2011.

13. Murray NP, Aedo S, Reyes E, Orellana N, Fuentealba C, Jacob O. A prediction model for early biochemical failure after radical prostatectomy based on the CAPRA-S score and the presence of secondary circulating prostate cells. BJU Int. 2015;118:556-62.

14. Cooperberg MR, Hilton JF, Carroll PR. The CAPRA-S score: a straightforward tool for improved prediction of outcomes after radical prostatectomy. Cancer. 2011;117:5039-46.

15. Loeb S, Carvalhal GF, Kan D, Desai A, Catalona WJ. External validation of the cancer of the prostate risk assessment (CAPRA) score in a single-surgeon radical prostatectomy series. Urol Oncol. 2012;30:584-9.

16. May M, Knoll N, Siegsmund M, Fahlenkamp D, Vogler H, Hoschke B, Gralla O. Validity of the CAPRA score to predict biochemical recurrence-free survival after radical prostatectomy. Results from a european multicenter survey of 1,296 patients. J Urol. 2007;178:1957-62. discussion 1962.
17. Wojciechowska J, Krajewski W, Bolanowski M, Krecicki T, Zatonski T. Diabetes and cancer: a review of current knowledge. Exp Clin Endocrinol Diabetes. 2016;124:263-75.

18. Lipscombe LL, Fischer HD, Austin PC, Fu L, Jaakkimainen RL, Ginsburg O, Rochon PA, Narod S, Paszat L. The association between diabetes and breast cancer stage at diagnosis: a population-based study. Breast Cancer Res Treat. 2015;150:613-20.

19. Briganti A, Karakiewicz PI, Chun FK, Suardi N, Gallina A, Abdollah F, Freschi M, Doglioni C, Rigatti P, Montorsi F. Obesity does not increase the risk of lymph node metastases in patients with clinically localized prostate cancer undergoing radical prostatectomy and extended pelvic lymph node dissection. Int J Urol. 2009;16:676-81.

20. Margel D, Urbach D, Lipscombe LL, Bell CM, Kulkarni G, Austin PC, Fleshner $\mathrm{N}$. Association between metformin use and risk of prostate cancer and its grade. J Natl Cancer Inst. 2013;105:1123-31.

21. Preston MA, Riis AH, Ehrenstein $V$, Breau RH, Batista JL, Olumi AF, Mucci LA, Adami HO, Sorensen HT. Metformin use and prostate cancer risk. Eur Urol. 2014;66:1012-20.

22. Bansal D, Bhansali A, Kapil G, Undela K, Tiwari P. Type 2 diabetes and risk of prostate cancer: a meta-analysis of observational studies. Prostate Cancer Prostatic Dis. 2013;16:151-8. S151.

23. Li Q, Kuriyama S, Kakizaki M, Yan H, Sone T, Nagai M, Sugawara Y, OhmoriMatsuda K, Hozawa A, Nishino Y, Tsuji I. History of diabetes mellitus and the risk of prostate cancer: the Ohsaki Cohort Study. Cancer Causes Control. 2010;21:1025-32.

24. Scallan JP, Hill MA, Davis MJ. Lymphatic vascular integrity is disrupted in type 2 diabetes due to impaired nitric oxide signalling. Cardiovasc Res. 2015;107:89-97.

25. Braadland PR, Ramberg H, Grytli HH, Tasken KA. $\beta$-adrenergic receptor signaling in prostate cancer. Front Oncol. 2014;4:375.

26. Goepel M, Wittmann A, Rubben H, Michel MC. Comparison of adrenoceptor subtype expression in porcine and human bladder and prostate. Urol Res. 1997:25:199-206.

27. Magnon C, Hall SJ, Lin J, Xue X, Gerber L, Freedland SJ, Frenette PS. Autonomic nerve development contributes to prostate cancer progression. Science. 2013;341:1236361

28. Andersen S, Richardsen E, Nordby Y, Ness N, Storkersen O, Al-Shibli K, Donnem T, Bertilsson H, Busund LT, Angelsen A, Bremnes RM. Diseasespecific outcomes of radical prostatectomies in Northern Norway; a case for the impact of perineural infiltration and postoperative PSA-doubling time. BMC Urol. 2014;14:49.

29. Lu H, Liu X, Guo F, Tan S, Wang G, Liu H, Wang J, He X, Mo Y, Shi B. Impact of beta-blockers on prostate cancer mortality: a meta-analysis of 16,825 patients. Onco Targets Ther. 2015;8:985-90.

30. Morelli MB, Amantini C, Nabissi M, Liberati S, Cardinali C, Farfariello V, Tomassoni D, Quaglia W, Piergentili A, Bonifazi A, et al. Cross-talk between alpha1D-adrenoceptors and transient receptor potential vanilloid type 1 triggers prostate cancer cell proliferation. BMC Cancer. 2014;14:921.

31. Hui H, Fernando MA, Heaney AP. The alpha1-adrenergic receptor antagonist doxazosin inhibits EGFR and NF-kappaB signalling to induce breast cancer cell apoptosis. Eur J Cancer. 2008;44:160-6.

32. Partin JV, Anglin IE, Kyprianou N. Quinazoline-based alpha 1-adrenoceptor antagonists induce prostate cancer cell apoptosis via TGF-beta signalling and I kappa B alpha induction. Br J Cancer. 2003;88:1615-21.

\section{Submit your next manuscript to BioMed Central and we will help you at every step:}

- We accept pre-submission inquiries

- Our selector tool helps you to find the most relevant journal

- We provide round the clock customer support

- Convenient online submission

- Thorough peer review

- Inclusion in PubMed and all major indexing services

- Maximum visibility for your research

Submit your manuscript at www.biomedcentral.com/submit
Biomed Central 